\title{
Superconducting Link Bus Design for the Accelerator Project for Upgrade of LHC
}

\author{
F. Nobrega, J. Brandt, S. Cheban, S. Feher, M. Kaducak, V. Kashikhin, T. Peterson
}

\begin{abstract}
The Accelerator Project for Upgrade of LHC (APUL) is a U.S. project participating in and contributing to CERN's Large Hadron Collider (LHC) upgrade program. Fermi National Accelerator Laboratory in collaboration with Brookhaven National Laboratory was developing sub-systems for the upgrade of the LHC final focus magnet systems. Part of the upgrade called for various lengths of superconducting power transmission lines known as SC Links which were up to $100 \mathrm{~m}$ long. The SC Link electrically connects the current leads in the Distribution Feed Boxes to the interaction region magnets. The SC Link is an extension of the magnet bus housed within a cryostat. The present concept for the bus consists of 22 power cables, $4 \times 13 \mathrm{kA}, 2 \times 7 \mathrm{kA}, 8 \times 2.5 \mathrm{kA}$ and $8 \times 0.6 \mathrm{kA}$ bundled into one bus. Different cable and strand possibilities were considered for the bus design including Rutherford cable. The Rutherford cable bus design potentially would have required splices at each sharp elbow in the SC Link. The advantage of the round bus design is that splices are only required at each end of the bus during installation at CERN. The round bus is very flexible and is suitable for pulling through the cryostat. Development of the round bus prototype and of 2 splice designs is described in this paper. Magnetic analysis and mechanical test results of the $13 \mathrm{kA}$ cable and splices are presented.
\end{abstract}

Index Terms-APUL, beam-guiding, focusing magnets, superconducting splice cables, superconducting link

\section{INTRODUCTION}

$\mathrm{T}$ HE primary function of the Superconducting Link (DSX) is to carry the current without any significant losses from the service module, located in the tunnel and supplies magnets with power and cryogens; to the Distribution Feed Box (DFX). The longest link was planned to be nearly $100 \mathrm{~m}$ long (IP5 right). Designing the DSX requires careful tunnel layout studies, choice of the superconducting bus and choice of efficient cryostat design. Due to the fact that the local environment of the tunnel is different in all four locations the design should be flexible enough to be able to accommodate the different layouts. Several options for the superconductor used in the bus were investigated like BISCO and YBCO based tapes and $\mathrm{Nb}_{3} \mathrm{Sn}$. The most cost effective and technically sound solution however was NbTi conductor. Our cryostat analysis showed that to achieve low heat leak solution we needed to build a solid pipe based cryogenic system [1].

Two bus designs were considered: i) Rectangular bus

Manuscript received 31 July 2010. Fermilab is operated by Fermi Research Alliance, LLC under Contract No. DE-AC02-07CH11359 with the United States Department of Energy.

Fred Nobrega et al. are with the Fermi National Accelerator Laboratory (Fermilab), P.O. Box 500, Batavia, IL 60510 USA (phone: 630-840-4271; fax: 630-840-3369; e-mail: nobrega@fnal.gov). design based on the current LHC Inner Triplet Quadruple bus and the 600 A corrector bus designs, ii) Round shape bus design graded to three different current types $(13 \mathrm{kA}, 8 \mathrm{kA}$, $3 \mathrm{kA}$ and $600 \mathrm{~A}$ ) by adjusting the cable cross section.

The splice joints must be mechanically stable, have low resistivity of less than one $\mathrm{n} \Omega$ and be able to solder and unsolder them several times [2].

\section{BUS TYPES}

\section{A. Superconducting Rectangular Bus}

The rectangular bus based on the present LHC Inner Triplet quadrupole and $600 \mathrm{~A}$ corrector bus designs would work well for the upgrade. To take advantage of existing Inner Triplet superconducting (SC) bus design and/or minimize the number of different types of bus rather than develop a bus for each power requirement, it is practical to service all magnets with only a low current $(0.6 \mathrm{kA})$ and high current bus (13 kA ). The LHC Inner Triplet Quadruple bus has been extensively studied [3]-[5]. It was demonstrated that it can be adequately protected at all current values.

Each high current cable is made of two Rutherford cables (one superconducting and one copper cable) sparingly soldered together. The cables were paired together to avoid cross talk between the different magnetic elements. The SC link bus configuration containing all 14 high current and 8 low (600 A) current cables are shown in Fig. 1.

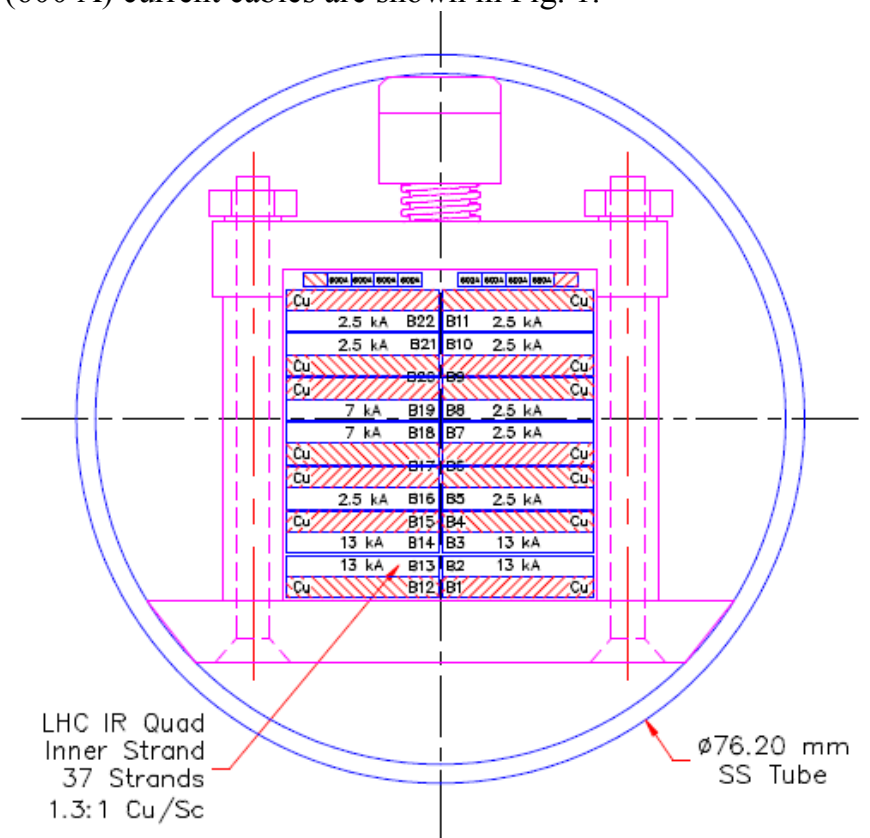

Fig. 1. The cable arrangement of the rectangular bus in the helium pipe with conductors grouped to improve cancellation of stray field. Currents corresponding to current lead design are shown. 
The rectangular option of the bus is a solution which has been tested and demonstrated its performance. It still has a few drawbacks in this application. It will be hard or impossible to install them into the SC link in one piece. It needs several splice junctions especially at each 90 degree bend. This will increase the installation time and the labor cost. More splices means increased vulnerability to installation mistakes.

\section{B. Superconducting Round Bus}

The round bus is very flexible and is suitable for pulling through the cryostat. The advantage of the round bus design is that splices are only required at each end of the bus during installation of the SC link at CERN including the longest link of $100 \mathrm{~m}$ at IP5. In order to minimize the amount of conductor used the cross section was optimized for three different current values. The number of strands varies depending on the current rating of the cable $(13 \mathrm{kA}, 7 \mathrm{kA}, 2.5 \mathrm{kA}$, and $0.6 \mathrm{kA})$. The $13 \mathrm{kA}$ cable uses 75 strands whereas the 600 A cable only uses 3 strands. The transposition pitch of the $600 \mathrm{~A}$ cable is approximately $25 \mathrm{~mm}$. Each of the 3 strand cables surrounding the copper core is twisted and each of these bundles surrounding its copper core is twisted resulting in a full transposition twist of the $13 \mathrm{kA}$ cable. The cross section of the bus was scaled from the IR quadrupole bus in such a way as to preserve the I/Ic ratio. The strand used for the round bus design is the same as was used in the LHC outer layer dipole coils, $1.95 \mathrm{Cu}: \mathrm{Sc}$ and $\varnothing 0.825 \mathrm{~mm}$.

Fig. 2 shows the cable design manufactured by New England Electric and Wire. Additional copper was added to each cable bundle to achieve the design value of $3.6 \mathrm{Cu}: \mathrm{Sc}$ ratio. The added copper was $\varnothing 0.26 \mathrm{~mm}(30 \mathrm{AWG})$ twisted wires. The nomenclature 56/30BC (5) means 56 bare $30 \mathrm{AWG}$ copper wires in 5 places. The copper wire size was selected so that one could distinguish the superconductor from the copper stabilizer during splice preparation.

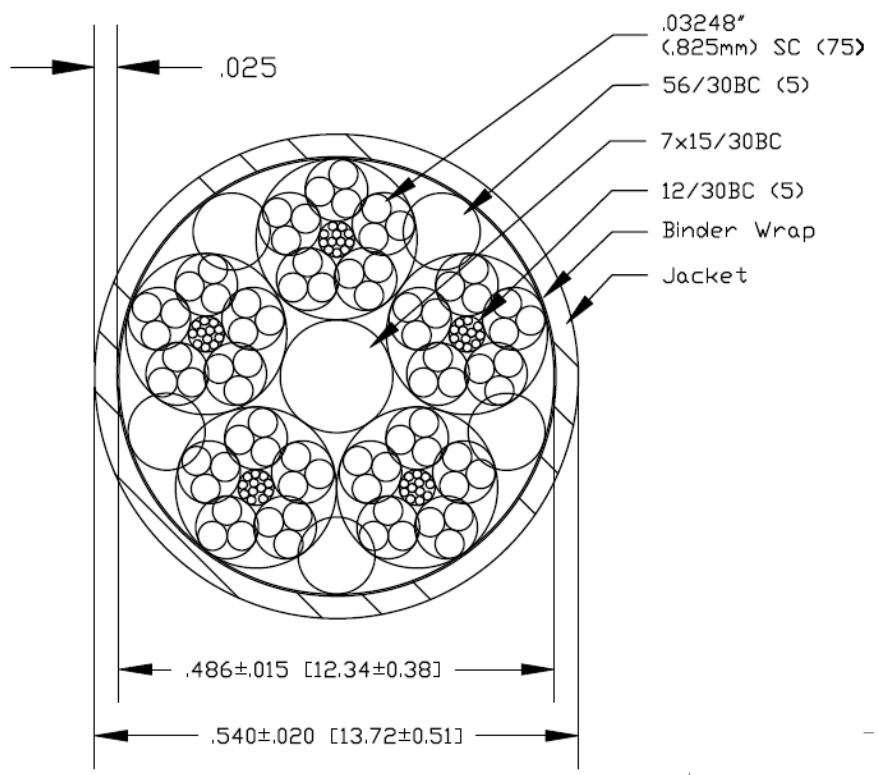

Fig. 2. $13 \mathrm{kA}$ bus cable design with LHC outer dipole $\varnothing 0.825 \mathrm{~mm}$ strand.

Fig. 3 is the SC link bus used to power the interaction region quadrupole, dipole, and corrector magnets. The SC link bus has a full transposition pitch as well as all the cables within the bus. Unlike the familiar Rutherford cable bus splice configuration the round cable splice design is new and needed to be studied and validated for use in the LHC. The $13 \mathrm{kA}$ cable has the highest number of strands. As such, it was chosen to be analyzed and tested. Each cable within the final package of the round bus in Fig. 3 is insulated with Kapton ${ }^{\circledR}$ and color coated Tefzel ${ }^{\circledR}$ ETFE. The final package of the round bus is insulated likewise.

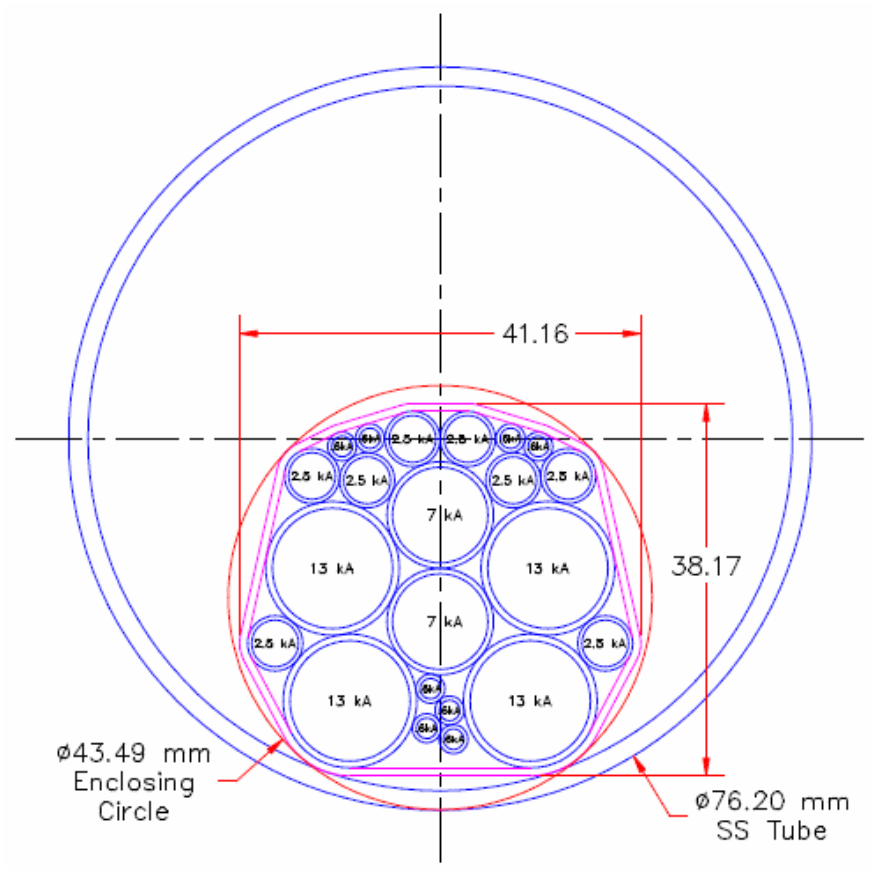

Fig. 3. An arrangement of a round bus in the helium pipe with conductors grouped to improve cancellation of stray field.

The round cable magnetic flux density and load lines at peak field values are shown in Fig. 4 and Fig. 5. The reference critical current density is $\mathrm{Jc}(5 \mathrm{~T}, 4.2 \mathrm{~K})=2500 \mathrm{~A} / \mathrm{mm}^{2}$. An equivalent pressure of 3.4 bar was calculated based on the magnetic flux which is approximately half the pressure generated within the rectangular bus design.

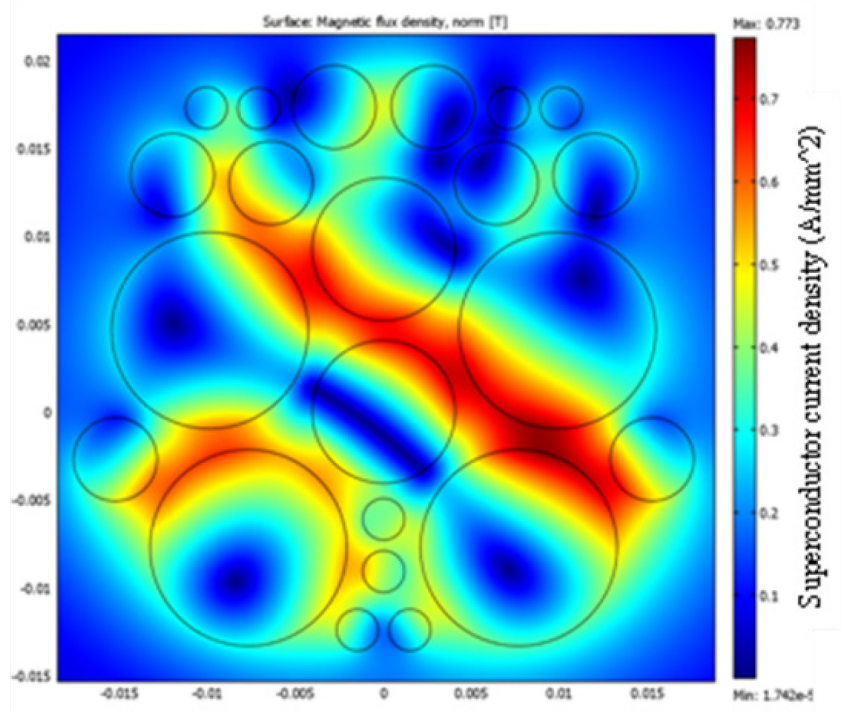

Reference critical current density is $\mathrm{Jc}(5 \mathrm{~T}, 4.2 \mathrm{~K})=2500 \mathrm{~A} / \mathrm{mm}^{2}$

Fig. 4. Round cable final arrangement flux density. 


\section{Bus Splice DesigN}

Two bus splice designs are needed, a splice connecting two round cables and a splice between a round cable and a Rutherford cable. The round cable to Rutherford cable splice design had a practical application in that it was used to connect to the power supply which used Rutherford cable. The strategy for each splice is the same in that they require good $\mathrm{SC}$ to SC contact between each cable. Also, since all of the bus cables have additional copper wire added for stability, the solder joint must have mechanical and electrical continuity through the copper stabilizer.

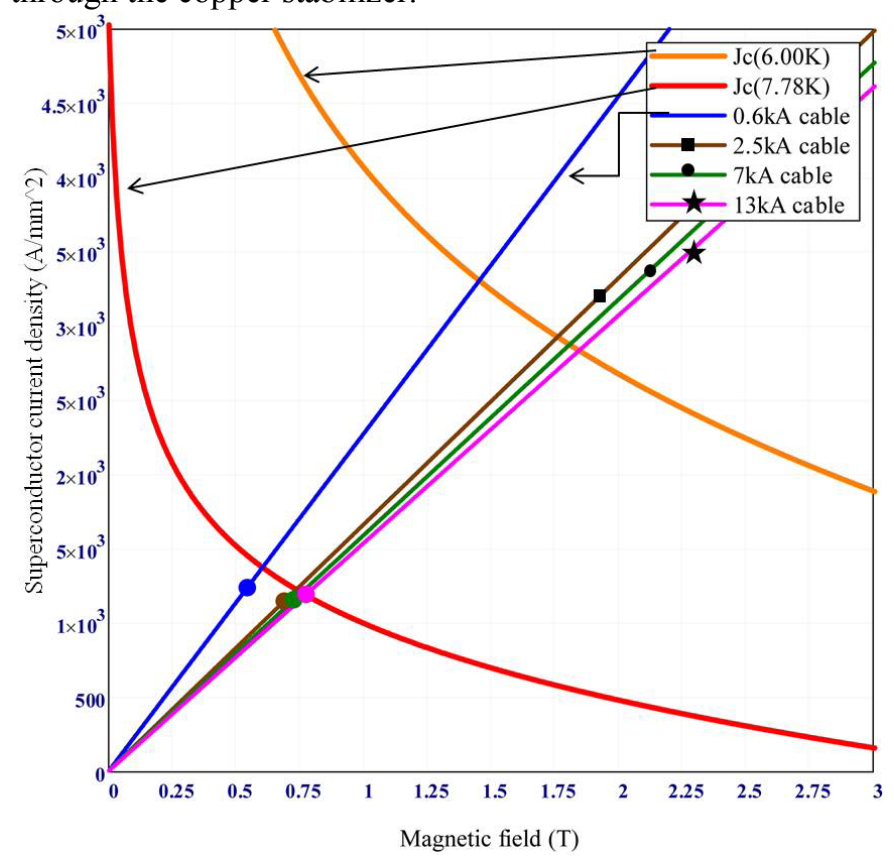

Fig. 5. Load lines at peak field values

\section{A. Round Cable to Round Cable Solder Joint}

Fig. 6 shows the round to round solder joint within a G-10 protective support housing. The ends of the G-10 support housing clamp the cable for mechanical strain relief.

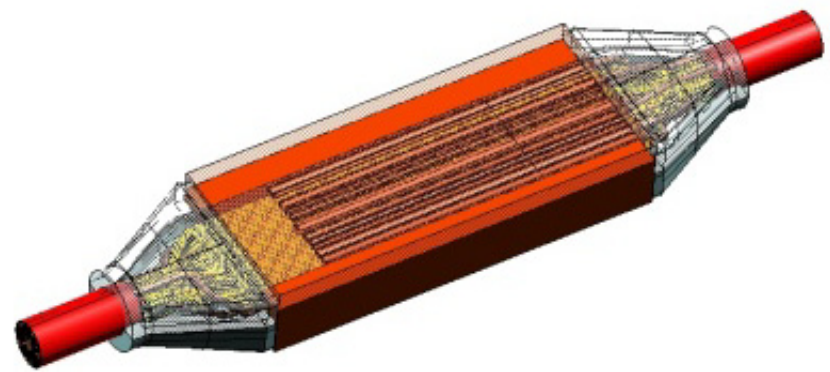

Fig. 6. Round cable to round cable solder joint within G-10 housing.

Fig. 7 shows the cross section of solder joint with the SC strands interleaved on top of the copper stabilizer wire bundle interleaved on the bottom. In this schematic, a technician separates all of the SC wires of both cable buses into two groups and pre-tins them in a flat orientation. The copper wire is also pre-tinned flat. Next, the first group of SC wires is laid into the solder fixture followed by the first group of the tinned $\mathrm{SC}$ wires from the other cable. This is repeated again for the remaining SC wires. A similar process is used to interleave the flat tinned copper stabilizer wire. Once assembled, the SC wires are interleaved and contacting its neighbor from the other SC cable. The assembly is ready to be soldered. Fig. 8 is a practice sample of a bus pre-tinned and ready to be interleaved with its mating bus. Fig. 9 is a practice sample of two $13 \mathrm{kA}$ cables soldered together.

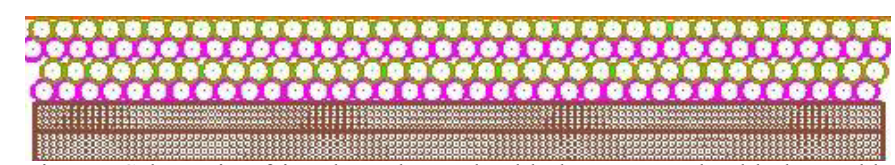

Fig. 7. Schematic of interleaved round cable bus to round cable bus solder joint.

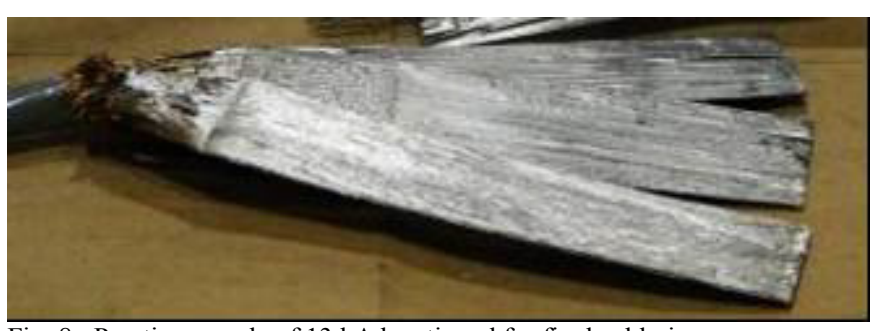

Fig. 8. Practice sample of $13 \mathrm{kA}$ bus tinned for final soldering.

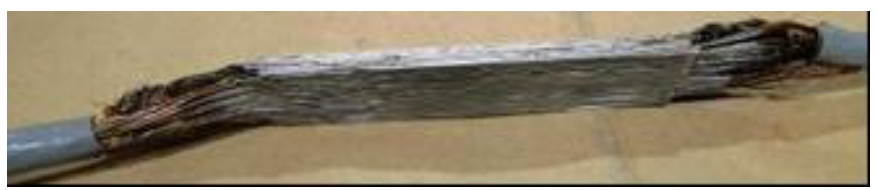

Fig. 9. Practice sample of $13 \mathrm{kA}$ bus cables soldered together.

\section{B. Round cable to Rutherford Cable Solder Joint}

The round cable to Rutherford cable solder joint is shown in Fig. 10. The top view is the solder joint within the G-10 protective housing. The middle schematic has a pre-tinned layer of SC wire from the $13 \mathrm{kA}$ cable as the top layer followed by a layer of Rutherford cable. The solder joint consists of three tinned layers of Rutherford cable interwoven with four layers of SC strand from the round bus. All of the bare copper wire is pre-tinned into a rectangular block.
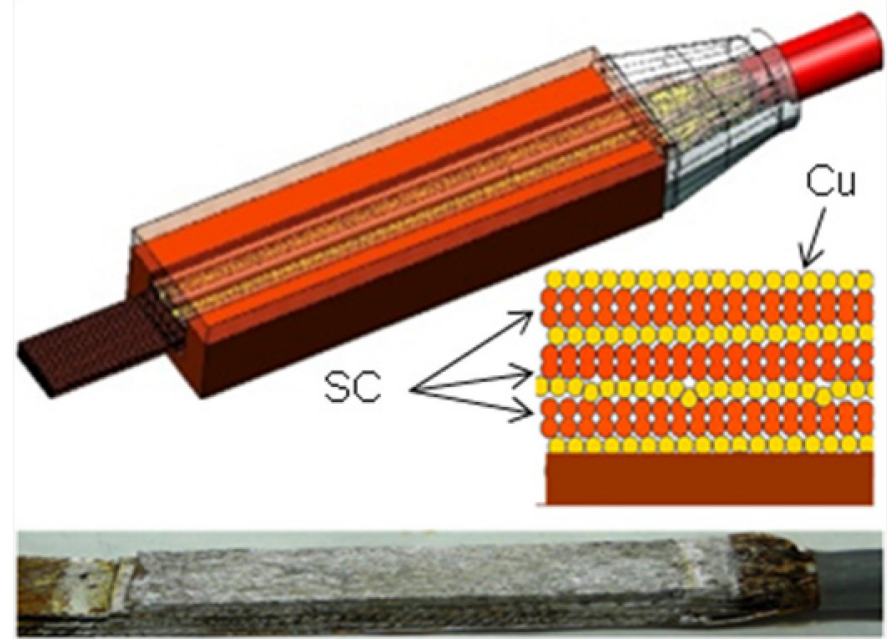

Fig. 10. Top, round cable to Rutherford cable splice model within a G-10 box. Middle, schematic of interleaved round bus to Rutherford bus solder joint, Bottom, practice sample of $13 \mathrm{kA}$ round cable soldered to three Rutherford cables. 


\section{Bus Splice Test}

\section{A. Bus Slice Test Setup}

The cold test at $4.5 \mathrm{~K}$ measured the splice resistance of the round cable to round cable and the round cable to Rutherford cable designs. Each of the three splices in the test setup had thermocouples on each end of the splice and a temperature sensor mounted in the middle of the splice as show in Fig. 11.

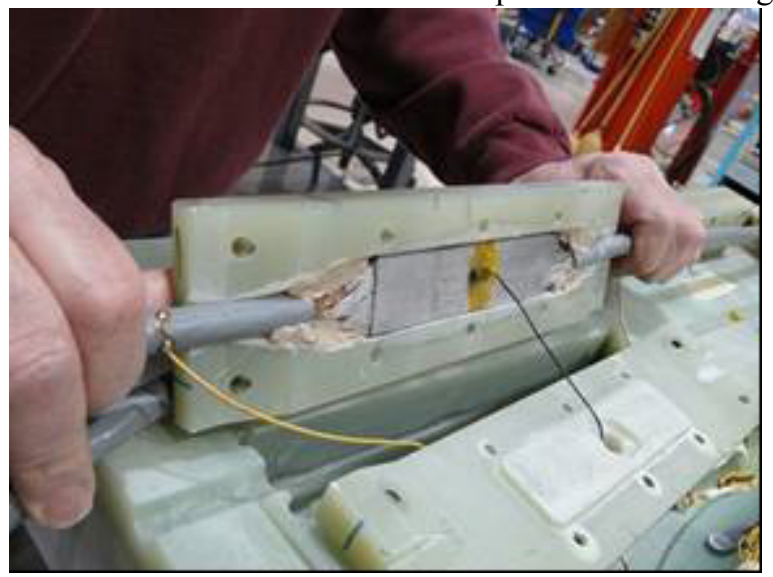

Fig. 11. Round to round $13 \mathrm{kA}$ instrumented splice within the test fixture.

There were two round to Rutherford cable splices and one round to round 13kA cable splice as shown in top view of Fig. 12. The two leads exiting to the right of the box are Rutherford cables that connect to the power supply. The bottom view is the final assembly that was tested. It includes three SC splices, and the $13 \mathrm{kA}$ cable wound in a dipole configuration to simulate the actual fields and forces that the cable could see in SC link operation. The dipole coil was also instrumented with thermocouples, temperature sensors and two spot heaters.

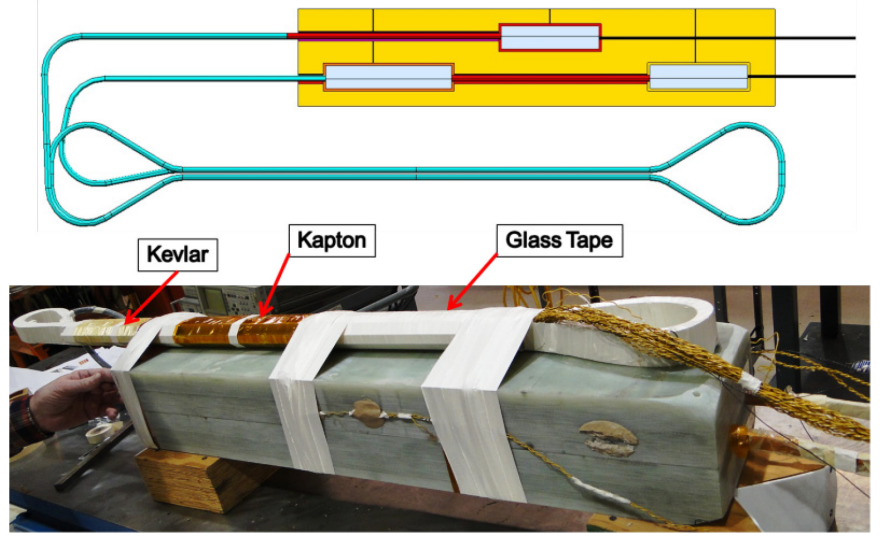

Fig. 12. Top, schematic of the test setup with three splice joints and cable wound in a dipole configuration. Bottom, actual device that was tested.

\section{B. Bus Splice Test Results}

The test fixture was cooled to $4.5 \mathrm{~K}$ in a liquid helium bath at Fermilab's Vertical Magnet Test Facility (VMTF). Both DC and $\mathrm{AC}$ tests were performed successfully up to $14 \mathrm{kA}$. The measured RRR value of the cable is 150 .

A special high current test was also performed after the liquid helium was removed from the test dewar. The temperature of the test setup was kept at $\sim 6 \mathrm{~K}$ and $1.3 \mathrm{bar}$ helium gas pressure. Steady operation under $14 \mathrm{kA}$ DC for more than an hour demonstrated that the bus and splice designs are satisfactory solutions for the planned SC Link design. The SC Link at CERN was planned to operate at 3 bar pressure and at $\sim 5.2 \mathrm{~K}$ maximum temperature.

Splice resistance measurements were performed by applying current steps up to $14 \mathrm{kA}$ and at each plateau measuring the voltages across the splices. Although precise measurements of the splices were not successful due to relatively high noise levels; we were able to set an upper limit on the splice resistances. The resistances for all three splices were less than $0.3 \mathrm{n} \Omega$ No temperature rise was observed using temperature sensors mounted near the center of each splice. These two facts further indicate that the splice design is adequate.

Quenches were successfully induced with spot heaters at 14 $\mathrm{kA}$ down to $10 \mathrm{kA}$. The maximum Quench Integral value was less than 150 MIIts and the maximum segment temperature where the quenches were initiated was less than $60 \mathrm{~K}$. At lower current values the spot heater was not powerful enough to initiate a quench. We can conclude that at high current values (10 kA and higher) quenches can be detected with 100 $\mathrm{mV}$ threshold values and the temperature rise in the bus during the detection and protection phase will be below $100 \mathrm{~K}$.

High current tests up to $25 \mathrm{kA}$ were performed to test the test setup rigidity. Two spontaneous quenches occurred at 23 $\mathrm{kA}$ and $25 \mathrm{kA}$. Both quenches originated at the same locations at the end loop segment that was held together with glass tape. Large spikes at the beginning of the quenches indicate that most likely explanation of the cause of the quench is bus motion.

After the test fixture was removed from the dewar it went through its initial visual inspection. The Tefzel ${ }^{\circledR}$ jacket surrounding the bus was cracked in two locations. The test fixture was completely disassembled and many more Tefzel ${ }^{\circledR}$ cracks were observed. The cause of the cracks is not known.

\section{CONCLUSION}

The bus splice designs were successfully tested at Fermilab's VMTF and are sufficiently adequate design solution for the SC link at CERN. The splices were tested up to $14 \mathrm{kA}$ in $6 \mathrm{~K}$ helium gas and up to $25 \mathrm{kA}$ in $4.5 \mathrm{~K}$ liquid helium.

Induced quenches from $10 \mathrm{kA}$ and higher can be detected with $100 \mathrm{mV}$ threshold values with the temperature rise in the bus during the detection and protection phase below $100 \mathrm{~K}$.

The round cable design proved to be effective and flexible, although the outer insulation jacket material requires further testing to verify its suitability for use.

\section{REFERENCES}

[1] M. Anerella et al., "Accelerator Project for Upgrade of LHC (APUL) Conceptual Design Report, http://apul-docdb.fnal.gov, January 2010.

[2] G. Ray, R. Bossert, "Quadrupole Magnet Inner Splice Project", FNAL internal report, 1999

[3] P. Bauer, et. al.,"LHC Interaction Region Quadrupole Busbars - Test series 1 - Revision", TD-99-059, January, 2001

[4] P. Bauer, et. al.,"LHC Interaction Region Quadrupole Busbars - Test series 2", TD-00-006, January, 2001

[5] P. Bauer, et. al.,"LHC Interaction Region Quadrupole Busbars - Test series 3", TD-00-019, March, 2000 